\title{
Intentional Enrichment of Subjective Well-Being
}

\author{
Dr. Mrunal A. Bhardwaj ${ }^{1 *}$, Shraddha A. Raravikar ${ }^{2}$
}

\section{ABSTRACT}

The key objective of a present article is to propose and explain "Intentional Enrichment technique" that provides activities to enhance the level of Subjective Well-being and to examine the study that is carried out to test the effectiveness of the technique. "Intentional Enrichment technique” assists individual to take up his responsibility of own happiness and actively try for it. The technique takes support of Fordyce 14 Happiness Fundamentals $(1977,1983)$ and Keyes's model of mental health (Keyes and Lopez, 2002). According to the technique, efforts for Intentional Enrichment can be divided into five ingredients i. e. Enrichment of the Self, Enrichment of Thoughts, Enrichment of Relationships, Enrichment of the Work, Enrichment of society. The field experiment is carried on one hundred and forty junior and senior college teachers. The technique proved efficient in improving the level of subjective well-being.

Keywords: Intentional Enrichment Technique, Subjective Well-being

A commonly shared goal of life for every individual is to be happy. It comprises seeking pleasure and avoiding negativities. But negativities are the part and parcel of life. In fact our pleasure would lose its very existence in absence of pain. Still excessive long-lasting physical or mental pain leads to negative physiological and psychological consequences. So we try to tip the balance of positive. Life bestows us with both joyous and saddening events, gratifying as well as disheartening relationships and more or less of material possessions. These situational factors along with internal qualities and subjective evaluations define our level of happiness. Despite physically and mentally taxing stressors and resulting pain and unhappiness we don't give up on a search for happiness. With the help of the adaptation process we overcome pain and try to remain happy. Apart from overcoming pain, we also strive for the pleasure. Some manage to remain stable and happy in chronic physical ailments and extremely poor environmental conditions. Some cannot be happy even in normal or affluent circumstances. Most people fall on the middle of the continuum. No matter wherever one stands the search goes on. But still in absence of major crisis, we see "not so happy" people around and many times we also remain so.

Our feelings change in reaction to the surrounding events. Simultaneously we judge the consequences in a momentary, domain specific as well as broader context of our life. Thus

\footnotetext{
${ }^{1}$ HOD and Vice-Principal, L. V. H. College, Nashik, MH

${ }^{2}$ Asst. Professor, M. V. P.'s ASC College, Ozar (Mig), MH

*Responding Author

(C) 2015 I M Bhardwaj, S Raravikar; licensee IJIP. This is an Open Access Research distributed under the terms of the Creative Commons Attribution License (http://creativecommons.org/licenses/by/2.0), which permits unrestricted use, distribution, and reproduction in any Medium, provided the original work is properly cited.
} 


\section{Intentional Enrichment of Subjective Well-Being}

subjective well-being involves various components: positive affect (many pleasant experiences) and low levels of negative affect (lesser unpleasant experiences), satisfaction pertaining to particular domains and satisfaction with life as a whole. If analyzed carefully, it becomes clear that the components are our passive reaction to the events. We have a very little, if any control over them. If we try to maximize positive affect with indulging ourselves, those effort gives momentary pleasure. Even ecstatic experiences make us happy for a short duration. With the process of adaptation very shortly we return to the baseline. In the context of positive affect the process is somewhat undesirable but it helps us to sustain pain and survive in extremities. To some extent negativities can be avoided but many times they keep falling and we become passive recipients left helpless. The satisfaction in important domains of life like relationships, work, and finances are also partially dependent upon significant interpersonal and environmental interactions. And satisfaction with life as a whole is a sum of these components. Given the lack of total control over all these factors, it's better to be self-reliant in our pursuit of happiness. Of course total self-reliance is unrealistic, impossible and somewhat abnormal goal; at least we should be aware of our ability to enhance our sense of well-being. An effort should be done to change overall evaluation of life by changing our perspective, strengthen ourselves emotionally and achieve highest possible emotional resistance. In short to do every possible thing to remain emotionally fit. Just as we keep our body fit with food nutrients and exercise, we should actively nurture our mind. At the outset, we must actively assume our responsibility to keep oneself happy and perseveringly keep trying. The ultimate goal shall be to make life worthwhile through self-efforts i.e. Intentional Enrichment. A rationale behind effort is the incompatibility of positive and negative emotions. The potential effects of negative experiences can be offset by positive emotions such as joy and contentment. Fredrickson, Mancuso, Branigan, \& Tugade (2000) have found evidences of "undoing" potential of positive emotions. Fredrickson and Losada (2005) also found that a mean ratio of 2:9 positive to negative emotions predicts human flourishing. Thus environmental, situational and interpersonal negativities can be offset by self gifted positive experiences and cumulative effects of such persistent efforts would invigorate mental health and enhance well-being.

The key objective of this present article is to propose and explain "Intentional Enrichment technique" that provides such activities and to examine the study that is carried out to test the effectiveness of the technique.

\section{Intentional Enrichment Technique}

According to Lyubomirsky and colleagues, $50 \%$ of a person's happiness is determined by genetic factors and another $10 \%$ is determined by circumstances. This still leaves $40 \%$ for the effects of intentional activity. Intentional activities mean those activities that are consciously chosen and require sustained efforts. "Intentional Enrichment technique" assists individual to take up his or her responsibility of own happiness and actively try for it. The technique takes support of Fordyce 14 Happiness Fundamentals $(1977,1983)$ and Keyes's model of mental health (Keyes and Lopez, 2002). It is an effort to provide simple tools to gain the much prized 


\section{Intentional Enrichment of Subjective Well-Being}

outcome i. e. to be happy from within and without superficial support of worldly materials and without relying unduly heavily on others for our happiness. The tactics are designed on the basis of 'Intentional Enrichment Technique'.

The efforts for Intentional Enrichment can be divided into five ingredients-

1. Enrichment of the Self

2. Enrichment of Thoughts

3. Enrichment of Relationships

4. Enrichment of the Work

5. Enrichment of society

Initial requisites of Enrichment

1. Individual should be ready to take up his or her responsibility of own happiness

2. Individual should take active efforts to boost his or her happiness

3. The intention should not be the avoidance of pain but to offset its effects through selfefforts

The diagrammed representation of the model is presented below:

\section{- Intentional Enrichment of Relationships}

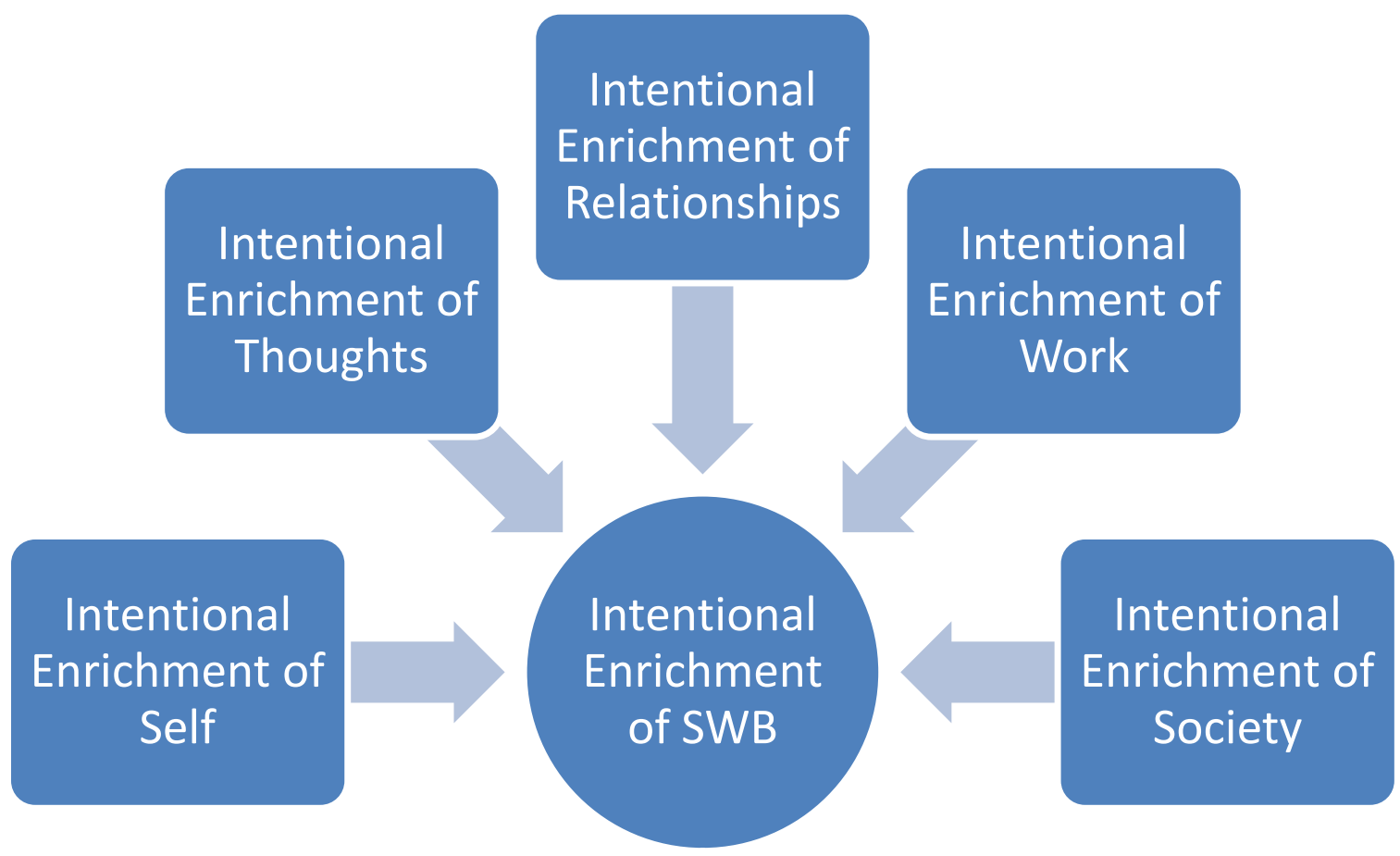

The model is based on Fordyce's 14 Happiness Fundamentals $(1977,1983)$ and Keyes' concept of Mental Health (Keyes and Lopez, 2002). 


\section{Significance and Implementation Enrichment of the Self}

The whole focus of the effort here is self. First attempt should be to improvise on oneself. It involves purging off mind, keeping it positive, developing and nurturing good habits and realizing ones potential. The aim is to raise positive affect, self knowledge, self esteem, optimism.

$\underline{\text { Activities }}$

1. Smiling

2. Possession List (count your blessings)

3. Giving small gifts (possibly self-made)

4. Smiling at strangers

5. Poison Pen

6. Humorous literature

7. SWOT

8. Accept and cheer the self

9. Goal-setting

10. Schedule for pursuing greatest passions

\section{Enrichment of Thoughts}

Albert Ellis has truly said that we feel the way we think. Though all events are not controllable, our evaluation of them defines our emotions. So with our thoughts we can make the dark things lighter. It also helps to maintain positive emotions and being resilient. The goal is to increase positive affect and optimism.

$\underline{\text { Activities }}$

1. Demonstration of "We feel the way we think"

2. Understanding Albert Ellis's ABC

3. Story critique

4. Re-evaluation of 5 negative life events

5. Reminiscing

6. Deliberate positive monologue

7. Auto suggestions

8. Think about what we don't have! ( look downward)

9. Wall paper

10. Find pleasure in taken for granted things

\section{Enrichment of Relationships}

We have a strong desire to belong and to love. Close relationships give meaning to our existence so much so that they affect our identity, self esteem, sense of worth in particular and sense of well-being and health in general. Of many factors that contribute to well-being, only relationships consistently predict happiness across widely different cultures. So greater the 
efforts, greater will be the uplift. The effort is to strengthen the close ties, broaden social network, ensuing satisfaction, boost gratitude and helping.

\section{$\underline{\text { Activities }}$}

1. Gratefulness chits

2. Appreciation

3. Create a love account

4. Saying please and sorry

5. Forgiveness chits

6. Walk in others' shoe

7. Focus on others' virtue

8. Note and capitalize on special events

9. Writing to forgotten friends

10. Unconditional help

\section{Enrichment of the Work}

We spend two third of our time at work. More than half of our waking time is consumed by our work and related commuting. Also it decides our access to material resources, societal status and self image. Its enrichment will truly lead to rich life. The aim is to raise self esteem, gratitude and positive experiences.

$\underline{\text { Activities }}$

1. Using a decision tree

2. Search for a bigger meaning in work

3. Make a list of what work gives you

4. Dedicate and do your best

5. Congratulating oneself

6. Decorate the work setting

7. Optimum use of commuting time

8. Savor the path (Seek enjoyment rather than accomplishment)

9. Develop Intrinsic motivation

10. Mentoring

\section{Enrichment of society}

Till now, all the focus was on personal gratification. After certain limit the focus can prove selfish and stagnated. We own a great credit to people and environment around. So paying back is very satisfying to self and others. The efforts can lead to happiness of society in general. The noble intent is to raise self esteem, hope, helping, gratitude and happiness.

\section{Activities}

1. Search for a bigger meaning in life

2. Spread a smile

3. Tell a tale

4. Plant a tree 
5. Send plastic for reuse

6. Become a volunteer

7. Work on a cause

8. Lend an ear

9. Lend a book

10. Share your enrichment

\section{METHOD}

\section{Participants}

The one hundred and forty[140] junior and senior college teachers of Nasik, Maharashtra were selected as subjects according to the availability and willingness to participate in an experiment and assigned to two groups i. e. one control group and one experimental group,70 teachers in each group.

\section{Material and Procedure}

This field experiment was carried out in following steps:

1. The total 140 were selected as subjects according to the availability and willingness to participate in an experiment and assigned to two groups. i. e. one control group and one experimental group.

2. Pre- test: The verbal reports and scores on measures of subjective well-being were obtained (to get the initial base-line). The Satisfaction with Life Scale by Diener, Emmons, Larsen, and Griffin, (1985) was used for the purpose.

3. Manipulation of IV: Implementation of Intentional Enrichment Technique. The total 50 activities were given to the subjects.

4. Post-test: Again the verbal reports and scores on measures of subjective well-being were obtained (to know the difference between initial level of happiness and post to the implementation of Intentional Enrichment Technique). The Satisfaction with Life Scale by Diener, Emmons, Larsen, and Griffin, (1985) was used for the purpose.

\section{RESULTS}

\section{Preliminary Analysis}

We first examined Pre-Test level of Subjective Well-being expecting to find no difference. Not much difference in the initial level of Subjective Well-being was found in the control group $(\mathrm{M}=25.03)$ and treatment group $(\mathrm{M}=25.23)$.

\section{Hypothesis Test}

To test the hypothesis that the level of subjective well being would be greater in college teachers from Experimental group following Intentional Enrichment Technique than college teachers from Control group, we conducted $t$ test. As expected we found a significant difference between the means of pre-test $(M=25.23)$ and post-tests of treatment group $(M=27.86)$. The value 
standard sigma scores $(\mathrm{z}=1.68)$ exceeds the critical value of 1.65 (one-tailed test) at $5 \%$ level. But no significant difference was found between the means of pre-test $(M=25.03)$ and post-test $(\mathrm{M}=25.31)$ of the control group. The value of standard sigma course $(\mathrm{z}=0.22)$ does not exceed the critical value of 1.65 (one-tailed test) at 5\% level.

The table 1 contains the mean scores of treatment group as measured before the implementation of Intentional Enrichment Technique and the mean scores of treatment group after the implementation of Intentional Enrichment Technique. The table 2 contains the mean scores of control group at the beginning of experiment and mean scores of control group after the fifty days of the initial measure.

Table1. Mean and SD for pre-test and post-test of treatment group

$\begin{array}{lcr} & \text { Mean } & \text { SD } \\ \text { Pre-test } & 25.23 & 6.79 \\ \text { Post-test } & 27.86 & 8.12\end{array}$

Table2. Mean and SD for pre-test and post-test of control group

$\begin{array}{lcr} & \text { Mean } & \text { SD } \\ \text { Pre-test } & 25.03 & 7.85 \\ \text { Post-test } & 25.31 & 7.19\end{array}$

\section{DISCUSSION}

In the present study we tested the effectiveness of Intentional Enrichment Technique in enhancing subjective well-being. The statistical analysis showed that the technique proved efficient in improving the level of subjective well-being and served the purpose. However the care should be taken while generalizing the findings as an experiment is carried out on a sample of junior and senior college teachers that belongs to particular class of society.

\section{REFERENCES}

Baumgartner S. R. \& Crothers M. R. (2009); Positive Psychology. Pearson Education

ED Diener (2000). Subjective Wellbeing, A Science of Happiness and a Proposal for National Index American Psychologist Vol. 55, No 1, 34-43

Fordyce M. W. (1983). A Programme to Increase Happiness: Further Studies, Journal of Counseling Psychology, Vol. 30, No. 4 , 488-498

Keyes C. L. M. (2007). Promoting and Protecting Mental Health as Flourishing: A Complementary Strategy for Improving National Mental Health, American Psychologist, Vol. 62, No. 2, 95-108

Keyes, C. L. M. (2002). The mental health continuum: From languishing to flourishing in life. Journal of Health and Behavior Research, 43, 207-222

Lamers, S. M. A. (2012). Positive mental health: Measurement, relevance and implications. Gildeprint Drukkerijen, the Netherlands. 


\section{Intentional Enrichment of Subjective Well-Being}

Mangal, S. K. (2006) Statistic in Psychology and Education, New Delhi. Prentice Hall of India. Seligman M. (2004); Authentic Happiness. Free Press

Seligman M. (2012); Flourish. Free Press

Snyder C. R. \& Shane J. L. (2007); Positive Psychology. Sage Publications, South Asia Edition

Snyder C. R., Shane J. L. \& Pedrotti J.T. (2012); Positive Psychology. Sage Publications, South Asia Edition, second edition

Zechmeister J. S. Zechmeister E. B. \& Shaughnessy J. J.(2001); Essentials of Research Methods in Psychology. Tata McGraw-Hill Edition

\section{Web Resources}

http://education.ucsb.edu/janeconoly/ed197

http://greatergood.berkely.ed

www. ncbi.nlm.nih.gov

www.deakinedu.ac.in

www.excelcentre.com

www.fetzer.org

www.healthvision.net

www.healthvisionhypnosis.com

www.internalpsychology.illinois.edu/

www.iswb.org/

www.psychologytoday.com

www.sociology.emory.edu/

www.statisticssolutions.com

www.whqlibdoc.who.int 